\title{
In Vitro Fluid Secretion by Epithelium from Polycystic Kidneys
}

\author{
Jared J. Grantham, ${ }^{*}$ Min Ye, ${ }^{*}$ Vincent H. Gattone II, $\neq \|$ and Lawrence P. Sullivan ${ }^{\sharp \|}$ \\ ${ }^{*}$ Department of Medicine, Division of Nephrology and Hypertension, ${ }^{\ddagger}$ Department of Anatomy and Cell Biology, ${ }^{8}$ Department of \\ Physiology, and "Kidney and Urology Research Center, Kansas University Medical Center, Kansas City, Kansas 66160
}

\begin{abstract}
The size of the kidneys in patients with autosomal dominant polycystic kidney disease (ADPKD) is due in large measure to the accumulation of secreted fluid within thin-walled epithelial sacs. We measured the net transepithelial movement of liquid in response to forskolin in isolated, intact cysts excised from the surface of human ADPKD kidneys and in cultured, polarized monolayers of epithelial cells derived from ADPKD cysts. 10 excised cysts bathed symmetrically in control culture medium secreted fluid at a rate of $0.19 \pm 0.03 \mu \mathrm{l} / \mathrm{cm}^{2}$ per hour after stimulation with forskolin $(10 \mu \mathrm{M})$. Ouabain $(100 \mu \mathrm{M})$ addition to the cavity fluid did not change the rate of fluid secretion of 10 forskolin-treated cysts, but addition of the glycoside to the external bathing medium fluid of nine cysts decreased secretion to $-0.004 \pm 0.05 \mu \mathrm{l} / \mathrm{cm}^{2}$ per hour. 24 monolayers absorbed fluid (range -0.029 to $-0.412 \mu \mathrm{l} / \mathrm{cm}^{2}$ per hour); by contrast, fluid was secreted (range 0.074 to $1.242 \mu \mathrm{l} / \mathrm{cm}^{2}$ per hour) after stimulation with forskolin $(10 \mu \mathrm{M})$. Ouabain $(0.1 \mu \mathrm{M})$ in the basolateral but not in the apical medium inhibited fluid secretion. Forskolin increased the intracellular cyclic AMP content of ADPKD and MDCK monolayers by 236 and $196 \%$, respectively. Six ADPKD monolayers had stable lumen negative transepithelial electrical potential differences $\left(P_{t e}\right)$ of $-1.4 \pm 0.3 \mathrm{mV}$, positive short circuit currents (SCC) of $11.9 \pm 2.1 \mu \mathrm{Amp} / \mathrm{cm}^{2}$ and a tissue resistance $\left(R_{t e}\right)$ of $116 \pm 14 \mathrm{ohm} \cdot \mathrm{cm}^{2}$. Forskolin increased SCC to $15.5 \pm 1.9$ $\mu \mathrm{Amp} / \mathrm{cm}^{2}(P<0.005)$ and decreased $R_{\mathrm{te}}$ to $95 \pm 13 \mathrm{ohm} \cdot \mathrm{cm}^{2}$ $(P<0.05) ; P_{\text {te }}$ remained stable at $-1.4 \pm 0.3 \mathrm{mV}$. Ouabain $(10 \mu M)$ had no effect when added to the apical medium, but in the basolateral medium decreased SCC to $1.7 \pm 0.3$ $\mu \mathrm{Amp} / \mathrm{cm}^{2}$ and $\mathrm{PD}_{\text {te }}$ to $-0.2 \pm 0.1 \mathrm{mV}$. We conclude that ADPKD cells in surface cysts have the potential to absorb or to secrete solutes and fluid. CAMP-mediated fluid secretion from the basolateral medium into the lumen of surface ADPKD cysts may be driven by anion transport. (J. Clin. Invest. 1995. 95:195-202.) Key words: cyst • secretion • cation transport • anion transport • fluid transport
\end{abstract}

\section{Introduction}

Polycystic kidney disease is one of the few disorders in which the kidneys increase in size as renal function deteriorates. The

Address correspondence to Jared J. Grantham, M. D., Department of Medicine, Division of Nephrology and Hypertension, Sudler 4015, Kansas University Medical Center, 3901 Rainbow Blvd., Kansas City, KS 66160.

Received for publication 17 March 1994 and in revised form 12 September 1994.

J. Clin. Invest.

(C) The American Society for Clinical Investigation, Inc.

0021-9738/95/01/0195/08 \$2.00

Volume 95, January 1995, 195-202 massive renal enlargement is due primarily to the volume of liquid trapped within individual cysts; the contribution to total kidney volume of the epithelial cellular layer surrounding each cyst is quite small $(1,2)$. In the $\sim 70 \%$ of cysts that are not connected to tubules in the advanced stages of polycystic kidney disease, transepithelial secretion is the only mechanism by which fluid can accumulate within the cavity. Although the molecular mechanisms of fluid reabsorption have been vigorously pursued for decades, the process of net fluid secretion by mammalian renal tubular epithelia has received little attention. Fluid secretion has been unequivocally demonstrated in normal mammalian renal tubules and cultured renal epithelia (3), and recent studies $(3,4)$ indicate that the cellular mechanisms that promote net fluid secretion by cultured renal tubule epithelial cells are similar in many respects to those that have been described for classic secretory epithelia including distal colon (5), gallbladder (6), seminiferous tubule (7), and respiratory tract (8).

The role of the sodium pump (Na-K,ATPase) in electrolyte secretion by cyst-forming renal epithelial cells has been examined recently. Wilson et al. (9) observed that the unidirectional fluxes of isotopic sodium across cultured explants of human autosomal dominant polycystic kidney disease (ADPKD) ${ }^{1}$ cysts was consistent with the net secretion of sodium into the apical compartment of cysts. The finding that apical but not basolateral application of ouabain blocked the secretory flux of sodium, and the immunohistochemical localization of $\mathrm{Na}-\mathrm{K}$,ATPase predominately in the apical plasma membranes suggested further that the sodium pump was mislocated in cyst epithelial cells. These observations led to the conclusion that fluid secretion by cyst epithelial cells depends on the active transport of sodium into the cyst cavity.

Carone et al. (10) used immunohistochemistry to localize Na-K,ATPase in ADPKD kidney cysts, but reached different conclusions than Wilson et al. (9). Carone et al. found that Na$\mathrm{K}$,ATPase was distributed primarily on the basolateral surfaces of the epithelium lining the cysts in ADPKD kidneys that were processed for histological examination shortly after the kidneys were surgically removed. The enzyme was infrequently found within apical membranes of cyst epithelial cells. These findings are more in keeping with the observed location of Na-K,ATPase in secretory epithelia in general (5-8).

In the last analysis, knowledge of the amount and direction of net fluid transport is paramount in determining the molecular basis of abnormal function in cyst epithelial cells. Neither of the preceding studies $(9,10)$ determined the impact of $\mathrm{Na}$ $\mathrm{K}$,ATPase inhibition or the locus of action of ouabain on the net transport of fluid by cyst epithelial cells.

1. Abbreviations used in this paper: ADPKD, autosomal dominant polycystic kidney disease; F12, Ham's nutrient medium; MDCK, MadinDarby canine kidney; $\mathrm{PD}_{\mathrm{te}}$, transepithelial electrical potential difference; $\mathbf{R}_{\mathrm{te}}$, transepithelial electrical resistance; SCC, short-circuit current. 
We have shown recently that polarized monolayer cultures of epithelial cells derived from ADPKD cysts secrete fluid and electrolytes in response to forskolin stimulation $(11,12)$. Moreover, intact cysts excised from human ADPKD kidneys and maintained in vitro for several days secreted fluid in response to stimulation by forskolin and endogenous secretagogues that accumulated in cyst fluids (13). In the current study, we have used intact cysts, excised from the surface of human kidneys and cultured ADPKD monolayers to determine the effect of ouabain on net fluid secretion, transepithelial electrical potential and short circuit current.

\section{Methods}

Excised cysts. The methods used are identical to those described previously (13). Briefly, polycystic kidneys from four individuals with autosomal dominant polycystic kidney disease were surgically removed as part of a treatment program after each patient had given informed consent. The kidneys were sealed in a sterile bag, immersed in ice and shipped to the laboratory by overnight delivery. Individual surface cysts ranging in weight from 5 to $58 \mathrm{~g}$ were dissected from the surrounding parenchyma and placed in chilled nutrient tissue-culture medium containing physiologic concentrations of electrolytes (a combination of DME and Ham's F12 medium [DME-F12; Hazelton Biologicals, Lenexa, KS]) (13) until used later that day. 42 excised cysts were selected for the study (10 to 15 from each kidney).

The contents of each cyst were aspirated into a calibrated syringe to determine the volume. That volume was used to calculate the total surface area of the cavity. Each cyst was rinsed with DME-F12 supplemented with 5\% fetal calf serum (Hyclone Laboratories, Logan, UT), insulin, transferrin, selenium, penicillin, and streptomycin (Sigma Chemical Co., St. Louis, MO) $(12,13)$. Fluid secretion was assessed in the presence and absence of cavity liquid. In 12 of the cysts from a single donor the DME-F12 medium was aspirated as completely as possible so as to collapse the cysts. Eight of the empty cysts were treated with forskolin $(10 \mu \mathrm{M})$, which activates adenylate cyclase, to confirm directly that fluid is secreted by the cyst epithelium. Four empty cysts were not treated with forskolin and served as controls. After $49 \mathrm{~h}$ the secreted fluid was aspirated from the cysts to determine the rate of fluid secretion and the electrolyte composition of the secretate. $\mathrm{Na}, \mathrm{K}$, and $\mathrm{Cl}$ concentrations were estimated in microliter samples by automated analysis

In 30 other cysts from two donors, the DME-F12 rinse solution was removed and an amount of supplemented DME-F12 approximating one third of the original fluid volume was injected into the cysts. The needle track was occluded with a ligature. Each cyst was blotted to remove adherent liquid, weighed on a Sartorius balance to the nearest $0.1 \mathrm{mg}$, transferred to an individual plastic vial containing $30-40 \mathrm{ml}$ of supplemented DME-F12 and incubated in a $5 \% \mathrm{CO}_{2}$ atmosphere at $37^{\circ} \mathrm{C}$ These cysts from two donors were used to determine the effect of ouabain, an inhibitor of Na-K,ATPase, on the stimulation of fluid secretion caused by forskolin. As described previously, the original fluid within the cysts was removed. The $\mathrm{Na}, \mathrm{K}$, and $\mathrm{Cl}$ concentrations of the natural cyst fluid were determined, retrospectively. The cavity was rinsed with DME-F12 which was removed completely. In preliminary studies, a concentration of ouabain in the basolateral medium sufficient to inhibit fluid secretion completely was determined $(100 \mu \mathrm{M})$. The cysts filled with and bathed in serum-supplemented DME-F12 were divided into three groups. Forskolin $(10 \mu \mathrm{M})$ was added to the bath of all 30 cysts. Serum-supplemented DME-F12 containing ouabain (100 $\mu \mathrm{M}$ final concentration) was injected into 10 of these cysts. Ouabain was added to the basolateral medium of another 10 cysts and a third group of 10 cysts served as a control. After $24 \mathrm{~h}$ of treatment with forskolin and ouabain the cysts were blotted and reweighed. The fluid within the cysts was aspirated and the volume determined.

Cultured renal cells. Polycystic kidneys from four subjects were processed at different times. 20-40 randomly selected surface cysts containing clear fluid were dissected free of adherent tissue. The outermost walls of individual cysts were excised, minced with fine-tipped scissors and digested in collagenase (Worthington Biochem. Corp., Freehold, $\mathrm{NJ} ; 1 \mathrm{mg} / \mathrm{ml}$ DME-F12) for $6-18 \mathrm{~h}$ at $37^{\circ} \mathrm{C}$. The collagenase was removed and the cells were plated in T-75 flasks in supplemented DMEF12 medium. Colonies of epithelial cells extended from fragments of cyst wall within $24 \mathrm{~h}$. After $48 \mathrm{~h}$ the serum-supplemented medium was replaced with serum-free defined medium containing DME-F12 and insulin, transferrin and selenium (Collaborative Research Inc., Bedford, MA), penicillin, streptomycin and epidermal growth factor $(25 \mathrm{ng} / \mathrm{ml})$ (Sigma Chemical Co.) in order to retard fibroblast growth. The cells were allowed to grow in serum-free defined medium until they covered $\sim 50 \%$ of the surface. They were dispersed with trypsin, rinsed in DMEF12 and $10^{6}$ cells were plated onto individual Transwell-Col cell culture chambers (Costar Corp., Cambridge, MA; $24.5 \mathrm{~mm}$ diameter). The cells developed confluent monolayers within 5 to $6 \mathrm{~d}$ after which they were adapted in supplemented DME-F12 for another 3 to $4 \mathrm{~d}$ before study.

Some of the cells were frozen in DMSO and stored in liquid nitrogen for subsequent use.

Fluid transport measurements on cultured monolayers. The method used to measure fluid transport by monolayers of renal epithelial cells has been described in detail $(3,11,12)$. To initiate a study, medium was completely aspirated from the compartment bathing the apical surface of the monolayer and $200 \mu \mathrm{l}$ of supplemented DME-F12 were added. This apical fluid was covered with sterile mineral oil to prevent evaporation DME-F12 medium ( $2.5 \mathrm{ml})$ was added to the basolateral compartment. The monolayers were incubated for $24 \mathrm{~h}$ after which the fluid and oil in the apical compartment were completely collected and centrifuged at 2,000 rpm for $5 \mathrm{~min}$. The fluid collected in the bottom of the centrifuge tube was aspirated into a calibrated capillary tube and the volume determined. Fresh medium was added to the apical and basolateral compartments daily and the procedure was repeated until the study was completed. In this paired experimental design, each monolayer was studied in up to two control and one or more experimental periods. To determine the effect of agonists, the fluid transport rate in the 24-h period immediately preceding the addition of the secretagogue was compared with that of the experimental period. The rate of fluid secretion or absorption was calculated from the difference in volume between the $200 \mu \mathrm{l}$ of fluid added to the apical compartment and that collected $24 \mathrm{~h}$ later. Fluid recovery was $92-98 \%$ complete (12). Results are expressed as $\mu \mathrm{l}$ of fluid transported per $\mathrm{cm}^{2}$ area of monolayer (total area exposed, 4.71 $\mathrm{cm}^{2}$ ) per hour. By our convention, net fluid secretion into the apical compartment is a positive flux and net absorption is negative.

Forskolin, AVP, $\mathrm{PGE}_{2}$, and ouabain were obtained from Sigma Chemical Co. Human ADPKD cyst fluid was from a pooled collection obtained from numerous cysts that had been standardized to stimulate fluid secretion by MDCK monolayers at a rate $>0.3 \mu \mathrm{l} / \mathrm{cm}^{2}$ per hour.

Electrical measurements on cultured monolayers. Monolayers of confluent monolayers that had been adapted on Transwell-Col membranes for 2-3 wk were mounted in standard Ussing chambers and the transepithelial potential difference, $\left(\mathrm{PD}_{\mathrm{te}}\right)$, the short-circuit current (SCC), and tissue resistance $\left(\mathrm{R}_{\mathrm{te}}\right)$ were determined using techniques described previously $(14,15)$. Briefly, the monolayer and its supporting membrane were impaled on pins embedded in the face of one halfchamber and the membrane was cut free from the plastic wall of the Transwell. The face of each half-chamber was lightly coated with silicone grease to provide an electrical seal and to prevent the consequences of edge damage. Each half-chamber was connected to a thermostatted reservoir containing $10 \mathrm{ml}$ of the bathing solution which was circulated by a bubble lift mechanism. The solutions consisted of DME-F12 + $1 \%$ fetal bovine serum equilibrated with $95 \% \mathrm{O}_{2}-5 \% \mathrm{CO}_{2}$ and maintained at $37^{\circ} \mathrm{C}$. $\mathrm{PD}_{\mathrm{tc}}$ was measured with the use of bridges consisting of polyethylene tubing filled with $3 \%$ agar in $3 \mathrm{M} \mathrm{KCl}$ and connected to $\mathrm{Ag}-\mathrm{AgCl}$ electrodes via a $3 \mathrm{M} \mathrm{KCl}$ solution. Current was applied via agar- $\mathrm{KCl}$ bridges connected to platinum wire electrodes. The tips of the bridges used to measure $\mathrm{PD}_{\mathrm{te}}$ were positioned within 1 to $2 \mathrm{~mm}$ of the tissue. The tips of the bridges used to apply current were positioned at the rear 

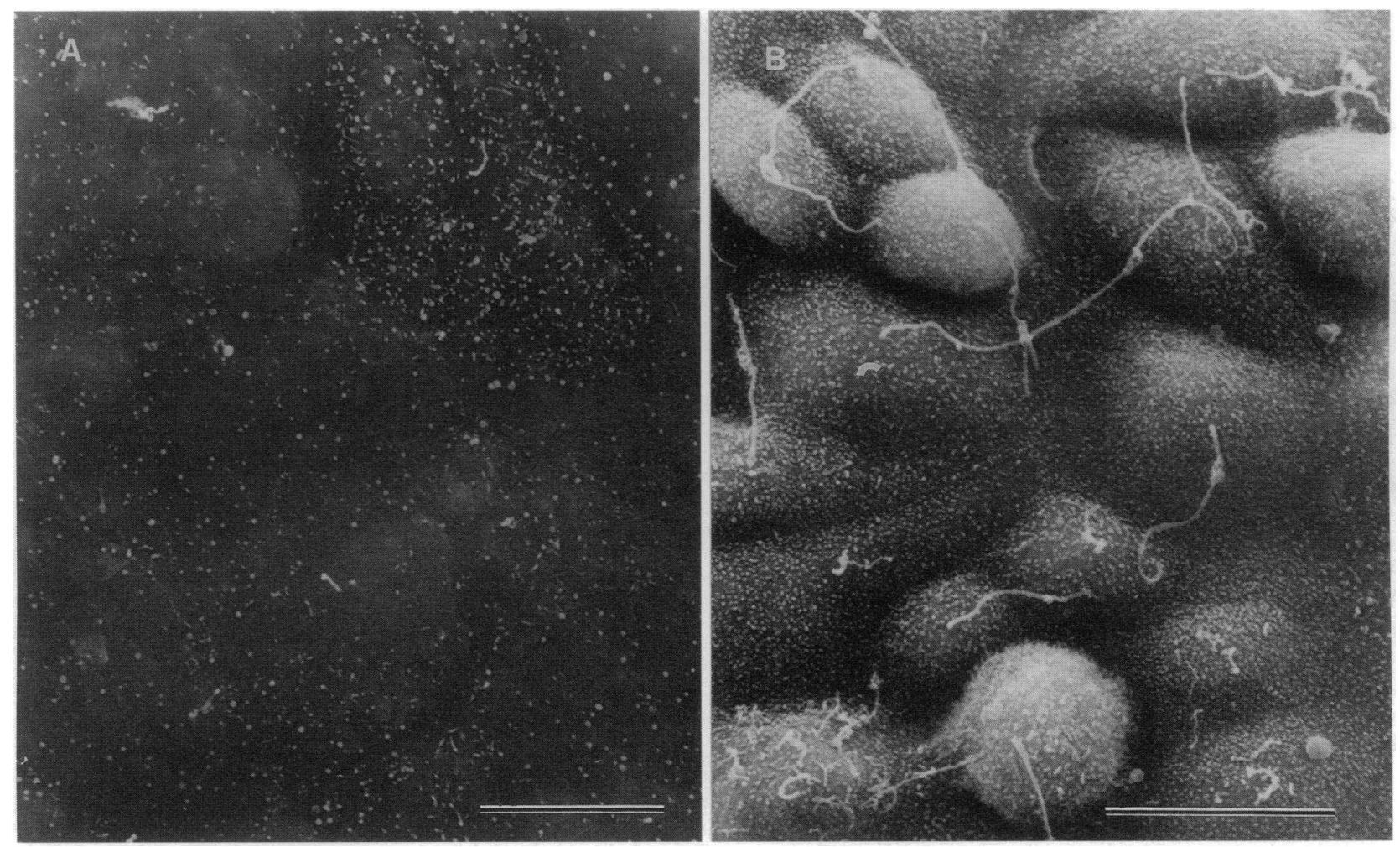

Figure 1. Electron micrographs of representative epithelia from six excised cysts and nine cultured ADPKD monolayers. $(A)$ Scanning electron micrograph of the inside surface of an excised cyst. $(B)$ Scanning electron micrograph of the apical surface of ADPKD cells cultured on a TranswellCol membrane. In each case, the epithelia were confluent. Cilia and microvilli confirmed the apical projection of the cell surface. Bars,10 $\mu \mathrm{m}$.

of the chamber. $\mathrm{PD}_{\mathrm{te}}, \mathrm{SCC}$ and $\mathrm{R}_{\mathrm{te}}$ were determined with the use of a voltage clamp apparatus (JWT Engineering, Overland Park, KS). The apparatus balanced the voltage electrodes and provided compensation for fluid resistance between the potential-sensing bridges and the tissue. $R_{t e}$ was determined by measuring the current required to clamp the $P_{t e}$ briefly at +1 to $+3 \mathrm{mV}$. We attempted to determine the resistance of the Transwell-Col membrane with the electrodes in the usual position in the absence of any cell layer and found it to be too low to measure accurately, thus no correction for the membrane was used.

The tissues were maintained in the short-circuited state and opencircuit voltage $\left(\mathrm{PD}_{\mathrm{te}}\right)$ and $\mathrm{R}_{\mathrm{te}}$ were determined at 1-5-min intervals After a 30-60-min period of equilibration, measurements were made in four sequential 20-min periods. Period 1 was the control period. Forskolin $(10 \mu \mathrm{M})$ was added to the basolateral solution at the beginning of period 2. Ouabain $(10 \mu \mathrm{M})$ was added to the apical solution at the beginning of period 3 and the same concentration was applied to the basolateral surface at the beginning of period 4 .

MDCK monolayers. A subculture of MDCK cells (16) were plated on Transwell-Col membranes and grown to confluence in supplemented DME-F12 medium as described previously $(11,17,18)$.

Cyclic adenosine monophosphate measurements. This method has been described previously (18). Briefly, confluent monolayers of ADPKD or MDCK cells that had been incubated in supplemented DMEF12 medium were treated with forskolin $(10 \mu \mathrm{M})$ in the basolateral bath for $2 \mathrm{~h}$. Untreated monolayers served as control. Individual monolayers were excised from the Transwell-Col chambers and the cyclic AMP was extracted with $0.5 \mathrm{ml}$ of $80 \%$ methanol $(\mathrm{vol} / \mathrm{vol})$. The methanol was evaporated at $37^{\circ} \mathrm{C}$ and the sample was reconstituted with $0.4 \mathrm{ml}$ of $0.05 \mathrm{M}$ sodium acetate, $\mathrm{pH}$ 6.2. Cyclic AMP was determined by radioimmunoassay (DuPont NEN, Boston, MA) and expressed as pmoles per monolayer

Electron microscopy. At the conclusion of each study, excised cysts and cultured monolayers were fixed in $2 \%$ paraformaldehyde and $2.5 \%$ glutaraldehyde for subsequent morphologic study. Specimens were selected at random for additional study. The primary fixative was removed by rinsing in phosphate-buffered saline and the specimens were postfixed in osmium and prepared for scanning electron microscopy as described previously (19).

Statistical tests. In experiments in which groups of intact cysts were treated differently, Kruskal-Wallis nonparametric ANOVA and Dunn's multiple comparison test were used. In experiments in which fluid secretion rates were measured sequentially in control and experimental periods, significance of the difference was determined by a paired $t$ test. In the experiments in which the effect of ouabain on fluid secretion was examined, significance of the differences was determined by one-way ANOVA and Bonferroni's multiple comparisons test. In the experiments in which electrical measurements were made on cultured monolayers in control and sequential treatment periods, repeated measures ANOVA and the Student-Newman-Keuls multiple comparisons test were used.

\section{Results}

Excised cysts. The sodium, potassium and chloride concentrations of 30 cysts from two different kidney donors were determined. Only one of the cysts had a sodium concentration less than $135 \mathrm{mEq} / \mathrm{liter}$. The sodium, potassium and chloride concentrations of this cyst were $33,4.7$, and $57 \mathrm{mEq} / \mathrm{liter}$, respectively. The range of electrolyte concentrations of the remaining 29 cysts were: $\mathrm{Na} 135-161, \mathrm{~K} 4.7-7.2$, and $\mathrm{Cl} 98-127 \mathrm{mEq} /$ liters. The six cysts selected for examination by scanning electron microscopy had intact epithelium covering the inner surface that was composed of relatively nondescript cells with short cilia and sparse microvilli. (Fig. $1 A$ ). None of the several hundred cells examined in these samples had a distinctive morphologic phenotype. 


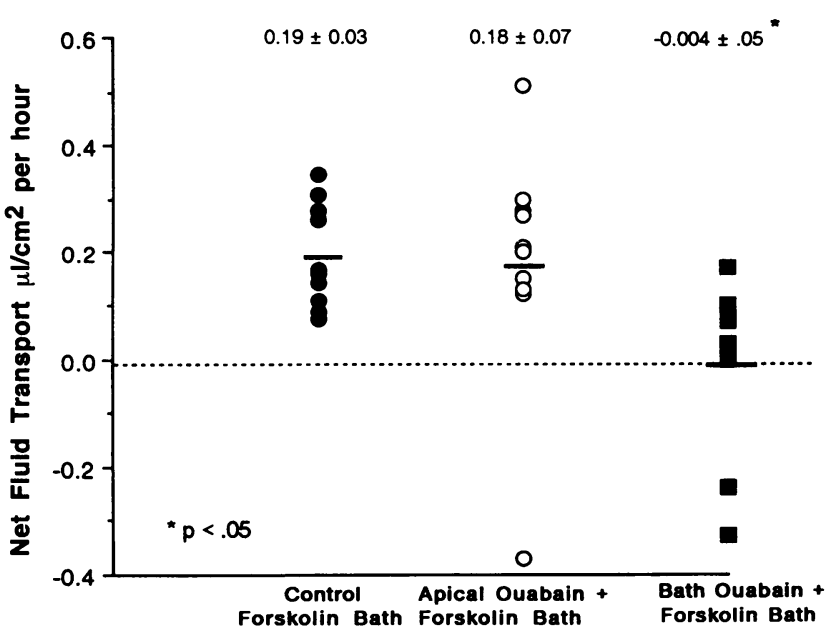

Figure 2. Effect of ouabain on forskolin-stimulated fluid secretion in intact ADPKD cysts. 10 different cysts were initially studied in each condition. One cyst with an unusually large rate of absorption in the bath ouabain group was excluded from the figure (see text for additional details). Horizontal bars show mean values. Values above data points are mean \pm SEM. Significance of difference from control determined by Kruskal-Wallis nonparametric ANOVA.

The relation between the change in cyst weight and the change in the volume of fluid within 45 cysts drawn from this and a previous study was described by the linear regression, cyst weight $(\mathrm{g})=0.055+1.026$ (cyst volume, $\mathrm{ml}), \mathrm{R}^{2}=0.88$. Thus, in the current study we assumed that changes in cyst weight reported changes in cyst cavity volume. The apical surface area of the cysts was estimated from the initial volume of fluid contained within the cyst, assuming spherical geometry.

In one set of ADPKD excised cysts, fluid was aspirated from the lumen as completely as possible. These cysts were incubated in supplemented DME-F12 medium for $49 \mathrm{~h}$ to determine the extent to which forskolin stimulated the net accumulation of liquid within the empty cavities. In the absence of forskolin, fluid accumulated within the cysts at a very low rate, $0.092 \pm 0.1 \mu \mathrm{l} / \mathrm{cm}^{2}$ per hour $(n=4)$. By contrast, forskolin stimulated fluid secretion to a mean rate of $0.308 \pm 0.04 \mu \mathrm{l} / \mathrm{cm}^{2}$ per hour $(n=8)$, which was significantly greater than zero $(P$ $<0.001)$. The fluid collected from the 12 cysts was combined into four separate pools $(0.75-1.48 \mathrm{ml}$ each) in order to have sufficient volume to estimate the electrolyte content of the liquid. The mean concentrations of $\mathrm{Na}(157 \mathrm{mEq} / \mathrm{liter}), \mathrm{K}(5.0$ $\mathrm{mEq} / \mathrm{liter})$ and $\mathrm{Cl}(130 \mathrm{mEq} / \mathrm{liter})$ of the pooled cyst fluids were similar to those of 12 individual samples of basolateral medium (153, 4.6, $128 \mathrm{mEq} /$ liter, respectively), providing qualitative evidence that $\mathrm{Na}$ and $\mathrm{Cl}$ were the principle electrolytes in the secreted fluid.

30 intact cysts from two ADPKD kidneys were incubated for $24 \mathrm{~h}$ in symmetrical, supplemented DME-F12 medium. Addition of forskolin $(10 \mu \mathrm{M})$ to the basolateral medium of one group of 10 cysts caused fluid to be secreted at a rate of $0.194 \pm 0.038 \mu \mathrm{l} / \mathrm{cm}^{2}$ per hour (Fig. 2). In a second group of 10 cysts ouabain $(10 \mu \mathrm{M})$ in the basolateral medium decreased the rate of forskolin-stimulated fluid secretion to $-0.14 \pm 0.15 \mu \mathrm{l} /$ $\mathrm{cm}^{2}$ per hour which was significantly less than the control rate of fluid secretion $(P<.05)$. (Deletion of one cyst with an unusually large negative fluid transport value $\left[-1.37 \mu \mathrm{l} / \mathrm{cm}^{2}\right.$ per hour] resulted in an average fluid secretion rate of $-0.004 \pm 0.053 \mu \mathrm{l} / \mathrm{cm}^{2}$ per hour. That deletion did not alter the statistical significance of the difference between groups.) By contrast, a third group of 10 cysts appeared to be insensitive to the addition of ouabain to the cavity medium. In these cysts the rate of net fluid secretion remained high at $0.18 \pm 0.07 \mu \mathrm{l} / \mathrm{cm}^{2}$ per hour, which was not significantly different from the control.

Polarized cultures of ADPKD epithelial cells. Primary cultures of epithelial cells derived from the walls of individual cysts on the surface of ADPKD kidneys were grown to confluence on Transwell-Col membranes. Nine preparations selected for examination by scanning electron microscopy had intact, confluent epithelium covering the upper surface of the TranswellCol membrane (Fig. $1 B$ ). The cells were relatively homogenous within and between individual preparations, but were more elongated and had longer cilia and more numerous microvilli than those of the intact cysts.

Fluid transport. Studies were conducted on monolayers that had been adapted in serum-supplemented DME-F12 medium (Table I, Fig. 3). In the control periods fluid was absorbed at rates ranging from 0.029 to $0.412 \mu \mathrm{l} / \mathrm{cm}^{2}$ per hour (Table I, Fig. $3)$. Addition of forskolin $(10 \mu \mathrm{M})$ for $24 \mathrm{~h}$ reversed fluid transport (range 0.312 to $1.212 \mu \mathrm{l} / \mathrm{cm}^{2}$ per hour). Three of the monolayers in Fig. 3 were treated with forskolin for an additional 24 $\mathrm{h}$; the rate of fluid secretion was maintained at $1.511 \pm 0.026 \mu \mathrm{l}$ $\mathrm{cm}^{2}$ per hour. $24 \mathrm{~h}$ after the removal of forskolin in one study (Table I, No. 269) fluid transport had reversed $(-0.253 \pm 0.005$ $\mu \mathrm{l} / \mathrm{cm}^{2}$ per hour). Arginine vasopressin and prostaglandin E2, both of which stimulate cyclic AMP formation and fluid secretion in MDCK cells through receptor-mediated mechanisms, decreased the rate of fluid absorption (Table I, No. 251), but net fluid secretion was not achieved.

A $15 \%$ concentration of human cyst fluid applied to the apical surface of the ADPKD monolayer decreased the rate of fluid transport from $-0.242 \pm 0.011(n=3)$ to $-0.089 \pm 0.016$ $(n=3) \mu \mathrm{l} / \mathrm{cm}^{2}$ per hour, $P<0.01$ (Table I). This same concentration of cyst fluid applied to the basolateral surface of another set of ADPKD monolayers derived from the same kidney reversed net fluid transport from $-0.257 \pm 0.029(n=3)$ to net secretion at a rate of $0.816 \pm 0.016(n=3) \mu 1 / \mathrm{cm}^{2}$ per hour, $P$ $<0.01$.

The addition of ouabain $(0.1 \mu \mathrm{M})$ to the basolateral medium of ADPKD monolayers for $24 \mathrm{~h}$ inhibited the fluid secretion response to forskolin leaving net fluid transport at a level indistinguishable from zero (Table II). By contrast, ouabain in the apical medium for the same length of time had no discernible effect on the rate of forskolin-stimulated net fluid secretion.

Bioelectric properties. Monolayers of cultured ADPKD cells from two patients were mounted in Ussing chambers and $\mathrm{PD}_{\mathrm{te}}, \mathrm{SCC}$ and $\mathrm{R}_{\mathrm{te}}$ were measured. The effects of forskolin followed by apical and then basolateral application of ouabain were determined. The results of one experiment is presented in Fig. 4 and the results of six experiments are summarized in Table III. $R_{\mathrm{te}}$ ranged from 86 to 175 and averaged $116 \pm 14$ $\mathrm{ohm} \cdot \mathrm{cm}^{2}$ indicating that electrical sealing of the monolayers was adequate. The baseline electrical $\mathrm{PD}_{\mathrm{te}}$ registered lumen negative with respect to the basolateral side in all six monolayers and averaged $-1.4 \pm 0.3 \mathrm{mV}$. A positive current flow from the basolateral to the apical surface of $11.9 \pm 2.1 \mu \mathrm{Amps} / \mathrm{cm}^{2}$ was required to reduce $\mathrm{PD}_{\text {te }}$ to zero (SCC). This indicates that the tissue actively transported net anion in the basolateral to apical direction (secretion) or net cation in the apical to basolateral 
Table I. Fluid Absorption and Secretion in Cultured ADPKD Epithelia

\begin{tabular}{|c|c|c|c|c|}
\hline Bath agonists & Experiment No. & Period 1 control & Period 2 agonist & Change agonist-control \\
\hline \multicolumn{5}{|c|}{$\mu / / \mathrm{cm}^{2} / \mathrm{h}$} \\
\hline Forskolin $10 \mu \mathrm{M}$ & 269 & $-0.412 \pm .008(3)$ & $0.312 \pm .032(3)$ & $0.724 \pm .037(3)^{8}$ \\
\hline AVP $10 \mathrm{mU} / \mathrm{ml}$ & 251 & $-0.107 \pm .014$ & $-0.048 \pm .016(3)$ & $0.058 \pm .013(3)^{*}$ \\
\hline PGE2 25 ng/ml & 251 & $-0.189 \pm .032$ & $-0.063 \pm .017(3)$ & $0.126 \pm .038(3)^{*}$ \\
\hline Cyst Fluid 15\% & 304 & & & \\
\hline Basolateral & & $-0.257 \pm .029$ & $0.205 \pm .016(3)$ & $0.459 \pm .001(3)^{*}$ \\
\hline Apical & & $-0.242 \pm .011$ & $-0.089 \pm .016(3)$ & $0.153 \pm .022(3)^{\ddagger}$ \\
\hline
\end{tabular}

Periods are $24 \mathrm{~h}$ in length; mean values $\pm \mathrm{SEM}$; (number of monolayers); $N D$, not done; secretion + , absorption $-\quad{ }^{*} P \boldsymbol{P}^{.05 ;}{ }^{\ddagger} P<.01 ; \quad{ }^{8} P$ $<.001$.

direction (absorption). These results are not consistent with the active secretion of cation. Forskolin $(10 \mu \mathrm{M})$ increased SCC and reduced $R_{t e}$ within seconds after its addition to the basolateral solution; $\mathrm{PD}_{\mathrm{te}}$ did not change. This result is consistent with the stimulation of anion secretion or cation absorption. The SCC and $R_{\mathrm{te}}$ averaged $15.5 \pm 1.9 \mu \mathrm{Amps} / \mathrm{cm}^{2}$ and $95 \pm 13 \mathrm{ohm} \cdot \mathrm{cm}^{2}$, respectively, before the addition of ouabain. Ouabain $(10 \mu \mathrm{M})$ added to the apical medium did not affect $S C C, P_{\text {te }}$ or $R_{t e}$. However, the subsequent addition of the same concentration of ouabain to the basolateral medium reduced SCC and $\mathrm{PD}_{\text {te }}$ to $1.7 \pm 0.3 \mu \mathrm{Amps} / \mathrm{cm}^{2}$ and $-0.2 \pm 0.1 \mathrm{mV}$, respectively. $R_{t e}$ was not significantly affected. The effect of ouabain is consistent with the cellular location of active $\mathrm{Na}-\mathrm{K}, \mathrm{ATPase}$ within the basolateral membrane, not the apical membrane.

Cyclic AMP content. Monolayers of ADPKD cells from a single donor and MDCK cells (an established renal epithelial cell line) (16-18) grown to confluence on Transwell-Col membranes in supplemented DME-F12 medium, exhibited baseline

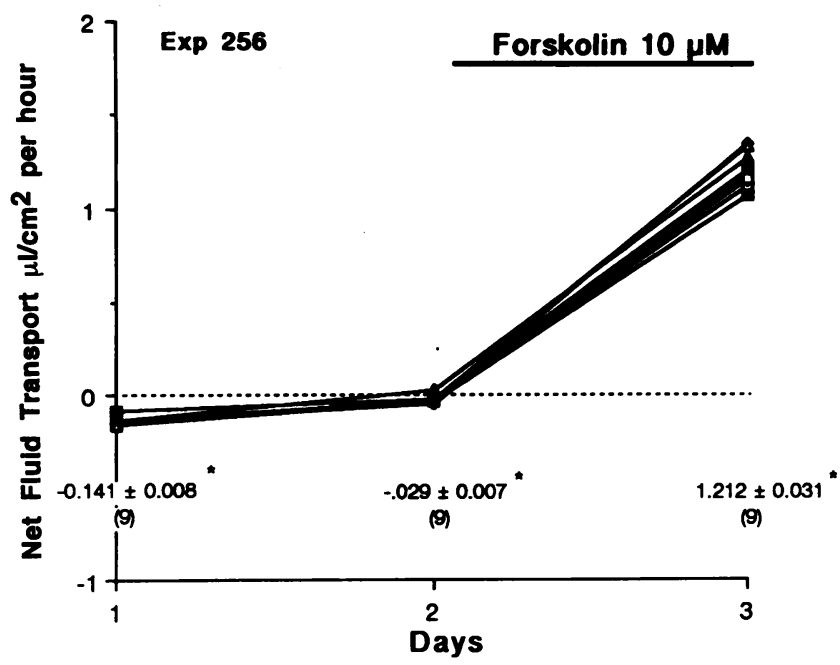

Figure 3. Effect of forskolin on fluid transport of ADPKD monolayers (Exp. 256). Nine monolayers were adapted in supplemented DME-F12 medium for $2 \mathrm{~d}$ after which forskolin $(10 \mu \mathrm{M})$ was added to the basolateral medium for $24 \mathrm{~h}$. Mean values of net fluid secretion are indicated for each day. Negative values indicate net absorption, positive values net secretion. Values below the data points are mean \pm SEM and number of specimens. Significance of difference from zero determined by paired $t$ test. $* P<0.005$ cyclic AMP contents of $11.8 \pm 1.3$ and $5.7 \pm 0.6$ pmoles/monolayer, respectively (Table IV). Addition of forskolin for $2 \mathrm{~h}$ increased the cyclic AMP content of ADPKD cells to 39.7 \pm 5.5 pmoles/monolayer and of MDCK cells to $16.9 \pm 6.8$ pmoles/ monolayer.

\section{Discussion}

The epithelial cells of mammalian renal tubules normally absorb relatively large quantities of electrolytes and water in the course of conserving glomerular ultrafiltrate. The major driving force for net solute and fluid absorption is the Na-K,ATPase or sodium pump that normally is distributed within the basolateral membranes of all renal tubule epithelial cells. The recent observation that intact, excised renal cysts, which derive from tubular epithelium, may absorb or secrete $\mathrm{NaCl}$ and liquid has presented an interesting puzzle in respect to defining the mechanisms by which a normally absorptive epithelia may secrete fluid in a pathological state such as $\operatorname{ADPKD}(3,13)$.

The cellular basis of fluid absorption or secretion in renal cysts is not clear. Several studies have illustrated that some surface cysts in ADPKD kidneys do not appear to have the capacity to generate steep transepithelial electrolyte gradients,

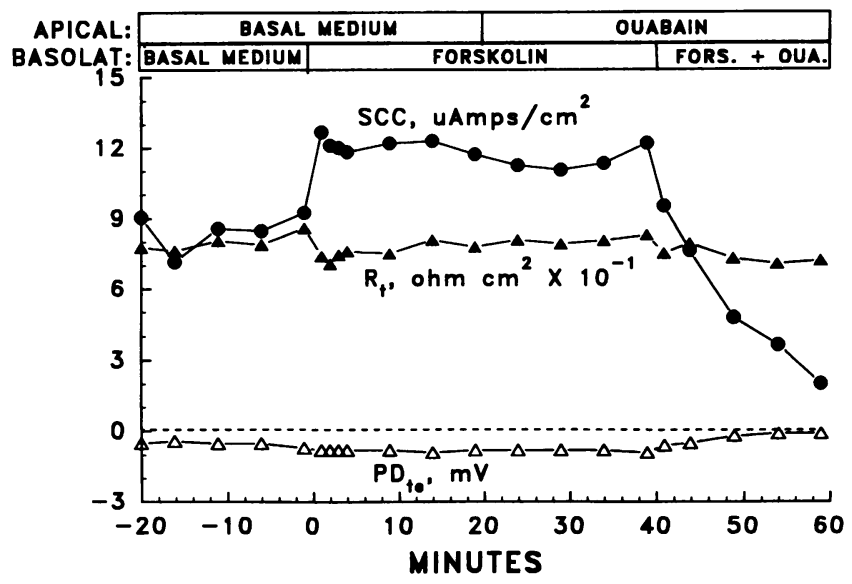

Figure 4. Effect of ouabain on forskolin-stimulated $\mathrm{SCC}, \mathrm{PD}_{\mathrm{te}}$ and $\mathrm{R}_{\mathrm{te}}$ of an ADPKD monolayer. After $20 \mathrm{~min}$ of stabilization, forskolin (10 $\mu \mathrm{M})$ was added to the basolateral medium, followed by the addition of ouabain $(10 \mu \mathrm{M})$ to the apical medium and then to the basolateral medium. 
Table II. Effect of Ouabain on Fluid Secretion of ADPKD Monolayers

\begin{tabular}{lccc}
\hline & Group 1 & Group 2 & Group 3 \\
\hline & & $\mu l / \mathrm{cm}^{2} / \mathrm{h}$ & $-0.296 \pm .018(3)$ \\
Period 1/Control & $-0.217 \pm .037(3)$ & $-0.189 \pm .044(3)$ & \\
$\begin{array}{l}\text { Period 2/Forskolin }(10 \mu \mathrm{M}) \\
\quad \text { No ouabain }\end{array}$ & $0.626 \pm .006(3)^{*}$ & & $0.021 \pm .008(3)^{\ddagger \S}$ \\
$\quad \begin{array}{l}\text { Basolateral ouabain }(0.1 \mu \mathrm{M}) \\
\text { Apical ouabain }(0.1 \mu \mathrm{M})\end{array}$ & & & $0.510 \pm .069(3)^{* \S}$ \\
\end{tabular}

Different from Period 1 control $* P<.01 ;{ }^{\ddagger} P<.05$. Forskolin versus basolateral ouabain; basolateral ouabain versus apical ouabain ${ }^{\S} P<.001$ Forskolin alone versus apical ouabain n.s.

so-called nongradient or "proximal" cysts, whereas others cysts maintain $\mathrm{Na}^{+}, \mathrm{K}^{+}, \mathrm{Cl}^{-}$, and $\mathrm{H}^{+}$gradients for many years (gradient or "distal" cysts) (19-24). In the current study the initial electrolyte composition of the natural fluid was used to profile the cysts. In thirty-seven of 38 cysts excised intact for this in vitro study, in which electrolyte measurements were made, the $\mathrm{Na}, \mathrm{K}$, and $\mathrm{Cl}$ concentrations were characteristic of the non-gradient type. The one cyst with low $\mathrm{Na}$ and $\mathrm{Cl}$ concentrations secreted fluid in vitro in response to forskolin at a rate $\left(2.58 \mu \mathrm{l} / \mathrm{cm}^{2}\right.$ per hour) which is similar to that of the four other nongradient cysts in the forskolin-treated group from that study (mean secretion rate $3.74 \pm 1.07 \mu 1 / \mathrm{cm}^{2}$ per hour). The sodiumprofiling method for characterizing electrolyte transport capacity may have overestimated the number of nongradient cysts in this study since the kidneys had been kept at $4^{\circ} \mathrm{C}$ for several hours. In any event, when the results of this and a previous study (13) are combined, 36 of 38 intact, excised cysts secreted fluid in response to forskolin or natural cyst fluid. Thus, we have not found significant heterogeneity in the in vitro performance of the intact cysts in respect to the capacity to secrete fluid after stimulation with secretagogues. It would appear that the surface cysts used in this and the previous study are capable of absorbing and secreting fluid in vitro, the vectorial direction of net fluid flow depending on the extent to which the respective secretory or absorptive solute transport mechanisms have been stimulated.

We found that $\mathrm{Na}$ and $\mathrm{Cl}$ were the principle electrolytes in the fluid secreted by excised cysts stimulated with the adenylate cyclase activator, forskolin. The current studies also revealed

Table III. Summary of Bioelectric Measurements in ADPKD Monolayers

\begin{tabular}{|c|c|c|c|}
\hline & $\mathrm{PD}_{\mathrm{te}}$ & SCC & $\mathbf{R}_{\mathrm{tc}}$ \\
\hline & $m V$ & $\mu \mathrm{Amp} / \mathrm{cm}^{2}$ & $\mathrm{Ohm}-\mathrm{cm}^{2}$ \\
\hline Control (0 min) & $-1.4 \pm 0.3$ & $11.9 \pm 2.1$ & $116 \pm 14$ \\
\hline $10 \mu \mathrm{M}$ Forskolin $(20 \mathrm{~min})$ & $-1.4 \pm 0.3$ & $15.5 \pm 1.9^{\S}$ & $95 \pm 13^{\S}$ \\
\hline $\begin{array}{l}10 \mu \mathrm{M} \text { Ouabain, apical (40 } \\
\mathrm{min})\end{array}$ & $-1.5 \pm 0.3^{*}$ & $15.9 \pm 2.7 *$ & $98 \pm 12 *$ \\
\hline $\begin{array}{l}10 \mu \mathrm{M} \text { Ouabain, basolateral } \\
(60 \mathrm{~min})\end{array}$ & $-0.2 \pm 0.1^{\ddagger}$ & $1.7 \pm 0.3^{\ddagger}$ & $89 \pm 12$ \\
\hline
\end{tabular}

Values are means \pm SEM, $n=6 . *$ Not different than forskolin value, $P>.05$. ${ }^{\ddagger}$ Significantly different than values at 0,20 , and 40 mins, $P<0.001$. ${ }^{8}$ Significantly different than control value, $P<0.05$. that epithelial cultures derived from the cells lining ADPKD cysts have the capacity to absorb as well as to secrete fluid in vitro. As in the intact, excised cysts (13) the monolayers absorbed fluid under basal conditions whereas fluid secretion was stimulated by forskolin. Other agonists (AVP, $\mathrm{PGE}_{2}$ ), known to stimulate the production of cyclic AMP and net fluid secretion in cultured renal epithelial cells, were less effective than forskolin in causing net fluid secretion in ADPKD monolayers (17 18). AVP and $\mathrm{PGE}_{2}$ added to the basolateral medium reduced fluid absorption, but fell short of causing net fluid secretion suggesting that the extent of cyclic AMP generation may have been insufficient to counteract the strong absorptive transport of solute by these cells. This raises the interesting possibility that net vectorial fluid transport in renal cysts may be determined by the concentration in extracellular fluids of endogenous substances capable of promoting solute and fluid secretion.

The addition to the basolateral medium of human cyst fluid, which contains a potent endogenous secretagogue, stimulated fluid secretion of ADPKD monolayers to approximately the same extent as forskolin. By contrast, the equivalent concentration of cyst fluid reduced absorption, but did not cause fluid secretion when it was added to the apical medium. In this regard, it is important to note that undiluted natural cyst fluid left within the cavity causes net fluid secretion in intact, excised cysts in vitro (13). Taken together, these results indicate that biologically active substances in cystic kidneys have the potential to promote fluid secretion when they are present in the extracellular fluids bathing basolateral or apical surfaces of cyst epithelial cells.

In the basal, unstimulated condition, the $\mathrm{PD}_{\mathrm{te}}$ of cultured ADPKD epithelium was oriented lumen negative, consistent with the net transport of a cation out of or an anion into the apical compartment. In view of the fact that fluid and solute were absorbed in the basal state (i.e., transported from apical medium to external bath), the lumen negative electrical $\mathbf{P D}_{\text {te }}$

Table IV. Effect of Forskolin on Cyclic AMP Content* of ADPKD and MDCK Monolayers

\begin{tabular}{|c|c|c|}
\hline & ADPKD & MDCK \\
\hline $\begin{array}{l}\text { Control } \\
\text { Forskolin } 10\end{array}$ & $11.8 \pm 1.3(5)$ & $5.7 \pm 0.6(3)$ \\
\hline$\mu \mathrm{M}$ & $39.7 \pm 5.5$ & $16.9 \pm 6.8(3)$ \\
\hline
\end{tabular}

* Cyclic AMP, pMoles/monolayer. 
was most compatible with the electrogenic transport of sodium. This finding is in accord with the observation of a negative lumen $\mathrm{PD}_{\mathrm{te}}$, a positive short circuit current and a net absorptive sodium flux in sections of unstimulated cyst walls removed from the kidneys of humans with ADPKD (22).

In the current study, absorption was completely reversed and net fluid secretion was sustained for at least $48 \mathrm{~h}$ in ADPKD monolayers stimulated with forskolin. Previous studies had shown that $\mathrm{Na}$ and $\mathrm{Cl}$ were the principal electrolytes in the fluid secreted by cultured ADPKD epithelium (12). Thus the forskolin-stimulated increase in the lumen-negative $\mathrm{PD}_{\mathrm{te}}$ in conjunction with a net secretory flux of solute and fluid was consistent with the electrogenic secretion of an anion, the most abundant of which was chloride. In the cysts of Table I and Fig. 2 that were treated with forskolin, the increment in net fluid flux caused by the agonist ranged from 0.72 to $1.24 \mu \mathrm{l} / \mathrm{cm}^{2}$ per hour, which is equivalent to a chloride flux ranging from 93 to 155 $\mathrm{nEq} / \mathrm{cm}^{2}$ per hour assuming isosmotic secretion of $\mathrm{NaCl}$. As indicated in Table III, forskolin induced an average increase in SCC of $3.6 \mu \mathrm{Amp} / \mathrm{cm}^{2}$ which is equivalent to a net chloride flux of $134 \mathrm{nEq} / \mathrm{cm}^{2}$ per hour. The similarity between the observed net chloride flux and the equivalent chloride flux estimated from the SCC supports the interpretation that in the forskolin-stimulated state transepithelial chloride transport may have a major role in the net secretion of fluid.

The measurements of SCC suggest that the changes in the direction of net solute transport in ADPKD epithelia can occur within seconds after stimulation with a secretagogue. This behavior is typically seen in cells in which transport processes are augmented by the activation of ion channels or the rapid implantation of preformed transporters into plasma membranes. These results do not seem to be in accord with mechanisms that depend on genomic activation of protein synthesis or sorting mechanisms that reposition transporters from one epithelial surface to another.

The response to ouabain of the ADPKD cysts and cultured epithelia in the current study indicates that the functional $\mathrm{Na}$ $\mathrm{K}, \mathrm{ATPase}$ responsible for generating transmembrane sodium gradients and thereby assisting the net movement of ions other than sodium is located primarily within the basolateral membranes of these preparations. The secretion of fluid and solutes by intact cysts was inhibited by ouabain only when the glycoside was added to the serosal (basolateral) medium. By the same token, the electrical $\mathrm{PD}_{\mathrm{te}}$ and SCC of forskolin-stimulated ADPKD monolayers were diminished when ouabain was present in the basolateral but not in the apical media. The effect of ouabain to inhibit completely the SCC and $\mathrm{PD}_{\mathrm{te}}$ indicates that the glycoside diminished the component of active sodium transport that was responsible for both net fluid absorption in the basal state and net fluid secretion after stimulation by forskolin. The current studies, therefore, do not support a role for functional Na-K,ATPase in the apical membranes of cyst cells since the electrical PD was inappropriate for net cation secretion, and ouabain had no effect on fluid and electrolyte transport when it was applied in the apical medium. It is conceivable that the $\mathrm{Na}-\mathrm{K}, \mathrm{ATPase}$ that has been immunohistochemically detected in some studies of ADPKD cell apical membranes $(9,10)$, may reflect functionally inactive, or immature enzyme, a possibility supported by the studies of Na-K,ATPase targeting in cysts formed in vitro with MDCK cells (25).

We cannot explain why Wilson et al. (9) found that ouabain inhibited $\mathrm{Na}$ transport when applied to the apical surface of cultured ADPKD epithelial cells and we did not. The procedures for culturing and passaging the cells differ in the two laboratories and these could be major factors. However, our examination of intact functioning cysts in conjunction with epithelia cultured from the cells lining those cysts lead us to propose an alternative hypothesis to that of Wilson et al. (9). Fluid secretion by epithelium derived from cysts bears strong resemblance to that proposed for other epithelia that secrete fluid in response to the stimulation of cyclic AMP production (5-8). In pulmonary cells, for example, the transmembrane conductance regulator (CFTR) is critically positioned to control the net movement of $\mathrm{Cl}$ across the apical membrane. Activation of the $\mathrm{Cl}$ channel by cyclic AMP leads to the secretion of liquid into the airways, whereas inhibition of this transporter promotes the net reabsorption of $\mathrm{Na}$ and fluid. CFTR is genetically inactivated in cystic fibrosis leading to decreased fluid secretion and uncontested fluid absorption tied to the active absorptive transport of $\mathrm{Na}$. Thus in contrast to cystic fibrosis where too little chloride and fluid are secreted, in ADPKD we propose that too much chloride and fluid are secreted by cyst epithelium.

Previous studies had indicated that cysts lined by functional epithelium have the capacity to absorb sodium in the absence of stimulation by secretory agonists $(22,26)$. An added bonus of the recent studies is the finding that ADPKD cyst epithelium can also absorb fluid. From this one may infer that by pharmacologically decreasing fluid secretion it may be possible to take advantage of the latent absorptive machinery of cyst epithelial cells to reduce the size of polycystic kidneys.

\section{Acknowledgments}

We thank Darren Wallace, Clarissa Haugness-Davidow, and R. David Gile for assistance. Mas Chiga, M. D. graciously performed the electrolyte analyses. The Polycystic Kidney Research Foundation coordinated the procurement of kidneys with the cooperation of Mark Aeder, Vic Robards, John MacElroy, and Michael Serene.

This work was supported by National Institute of Diabetes and Digestive and Kidney Diseases grant 45614 (J. J. Grantham), American Heart Association (Kansas Affiliate) (L. P. Sullivan), and the Polycystic Kidney Research Foundation (L. P. Sullivan).

\section{References}

1. Grantham, J. J., J. L. Geiser, and A. P. Evaan. 1987. Cyst formation and growth in autosomal dominant polycystic kidney disease. Kidney Int. 31:11451152.

2. Evan, A. P., and J. A. McAteer. 1990. Cyst cells and cyst walls. In: The Cystic Kidney. K. D. Gardner, Jr. and J. Bernstein, editors. Kluwer Academic Publishers, Boston, MA. 21-42.

3. Grantham, J. J. 1993. Fluid secretion, cellular proliferation, and the pathogenesis of renal epithelial cysts. J. Am. Soc. Nephol. 3:1843-1857.

4. Sullivan, L. P., D. P. Wallace, and J. J. Grantham. 1994. Coupling of cell volume and membrane potential changes to fluid secretion in a model of renal cysts. Kidney Int. 45:1369-1380.

5. Welsh, M. J., P. L. Smith, M. Fromm, and R. A. Frizzell. 1982. Crypts are the site of intestinal fluid and electrolyte secretion. Science (Wash. DC). 218:1219-1221.

6. Petersen, K.-U. 1993. Mechanisms of fluid secretion induced by cAMP and related agents in gallbladder. Dig. Dis. Sci. 38:1948-1949.

7. Leung, A. Y. H., and P. Y. D. Wong. 1994. The epididymis as a chloridesecreting organ. News in Physiological Sciences. 9:31-35.

8. Smith, J. J., and M. J. Welsh. 1993. Fluid and electrolyte transport by cultured human airway epithelia. J. Clin. Invest. 91:1590-1597.

9. Wilson, P. D., A. C. Sherwood, K. Palla, J. Du, R. Watson, and J. T. Norman. 1991. Reversed polarity of $\mathrm{Na}+\mathrm{K}, \mathrm{ATPase}$ mislocation to apical plasma membranes in polycystic kidney disease epithelia. Am. J. Physiol. 260:F420F430.

10. Carone, F. A., S. Nakamura, M. Caputo, R. Bacallao, W. J. Nelson, and 
Y. S. Kanwar. 1994. Cell polarity in human renal cystic disease, Lab Invest. 70:648-655.

11. Mangoo-Karim, R., M. E. Uchic, M. Grant, W. A. Shumate, J. P. Calvet, C. H. Park, and J. J. Grantham 1989. Renal epithelial fluid secretion and cyst growth: the role of cyclic AMP. FASEB (Fed. Am. Soc. Exp. Biol.) J. 3:26292632.

12. Ye, M., and J. J. Grantham. 1993. The secretion of fluid by renal cysts from patients with autosomal dominant polycystic kidney disease. $N$. Engl. J. Med. 329:310-313.

13. Neufeld, T. K., M. E. Grant, and J. J. Grantham. 1991. A method to measure the rate of net fluid secretion by monolayers of cultured renal epithelial cells. J. Tissue Culture Meth. 13:229-234.

14. Sullivan, L. P., J. M. Tucker, and M. J. Scherbenske. 1971. Effect of furosemide on sodium transport and metabolism in the toad bladder. Am. J. Physiol. 220:1316-1324.

15. McCabe, R. D., P. L. Smith, and L. P. Sullivan. 1984. Ion transport by rabbit descending colon: mechanisms of transepithelial potassium transport. Am. J. Physiol. 246:G594-G602.

16. Grantham, J. J, M. Uchic, E. J. Cragoe, Jr, J. Kornhaus, J. A. Grantham, V. Donoso, R. Mangoo-Karim, A. P. Evan, and J. McAteer. 1989. Chemical modification of cell proliferation and fluid secretion in renal cysts. Kidney Int. 35:1379-1389.

17. Grant, M., and J. J. Grantham. 1991. Arginine vasopressin stimulates net fluid secretion in a polarized subculture of cyst-forming MDCK cells. J. Am. Soc. Nephrol. 2:219-227.
18. Mangoo-Karim, R., M. Uchic, C. Lechene, and J. J. Grantham. 1989. Renal epithelial cyst formation and enlargement in vitro: dependence on cAMP. Proc. Natl. Acad. Sci. 86:6007-6011.

19. Takahashi, H, J. P. Calvet, D. Dittemore-Hoover, K. Yoshida, J. J. Grantham and V. H. Gattone. 1991. A hereditary model of slowly progressive polycystic kidney disease in the mouse. J. Am. Soc. Nephrol. 1:980-989.

20. Gardner, K. D., Jr. 1969. Composition of fluid in twelve cysts of a polycystic kidney. N. Engl. J. Med. 281:985-988.

21. Huseman, R., A. Grady, D. Welling, and J. Grantham. 1980. Macropuncture study of polycystic disease in adult human kidneys. Kidney Int. 18:375-385.

22. Perrone, R. D. 1985. In vitro function of cyst epithelium from human polycystic kidney. J. Clin. Invest. 76:1688-1691.

23. Gardner, K. D., Jr, J. S. Burnside, B. J. Skipper, S. K. Swan, W. M. Bennett, B. A. Connors, and A. P. Evan. 1992. On the probability that kidneys are different in autosomal dominant polycystic disease. Kidney Int. 42:11991206.

24. Gardner, K. D., R. H. Glew, A. P. Evan, J. A. McAteer, and J. Bernstein. 1994. Why renal cysts grow. Am. J. Physiol. 266:F353-F359.

25. Hammerton, R. W., K. A. Krezeminski, R. W. Mays, T. A. Ryan, D. A. Wollner, and W. J. Nelson. 1991. Mechanism for regulating cell surface distribution of $\mathrm{Na}^{+}, \mathrm{K}^{+}$-ATPase in polarized epithelial cells. Science (Wash. DC). 254:847-847.

26. Perrone, R. D., and M. L. McLaughlin. 1989. Cyst function in polycystic kidney disease: nongradient cysts. Clin. Nephrol. 32:113-118. 